BOOK REVIEW

\title{
Creative Aerobics: Fueling Imagination in the 21st Century
}

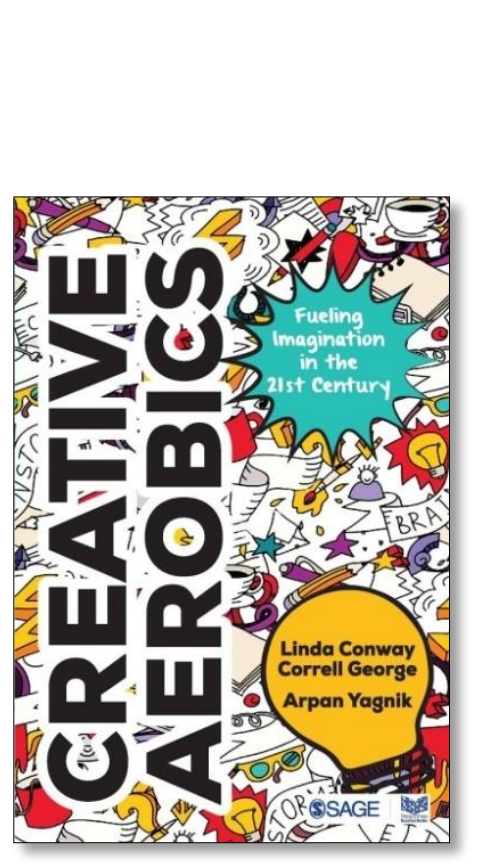

\author{
Dr. Sumit Narula* \\ Director, Amity School of Communication \\ Amity University Madhya Pradesh, Gwalior
}

What a refreshing way to start your day with the following two exercises:

(a) Give ten new names for a pen, using the same or a different characteristic

(b) Give similarities between a ballpoint pen and a shopping cart

Creative Aerobics: Fueling Imagination in the $21^{\text {st }}$ Century helps us learn how to get in touch with our inner creativity. There are many more exercises like the ones above throughout the entire book, which in the end will give your mind confidence in the idea that 'I, still, can be creative'. This book has exercises that are simple and quick and are in conjunction with each other. They are very specific in focus and save time.

I feel comfortable in saying that, when you finish the exercises, the solution will be in place. In fact, there will be multiple solutions. Creative
Aerobics gives us the purpose to discover fresh, unconventional ideas that will cut through the clutter of information overload. It also helps us learn how to come up with new phrases with greater impact for various uses such as headline creation.

The best part of the book is when it delves into discovering similarities between a giraffe and a paper lunch bag. This is amazing, and it rouses your left-brain with a jolt. Creativity is all about looking for new connections and Creative Aerobics is all about making it happen. This is the theme of this nicely crafted book. The book also has exercises related to fueling one's imagination. Always remember that Imagination is the highest flight a man can fly. There are no wrong answers.

As you arrive at your answers after doing the exercises, there is a reward awaiting you, which makes you feel elated.

Finally, the book has a short learning curve for every reader. All the exercises in the book are interconnected. This very interconnection is the innovative addition to, and time-shortening improvement over, the single dimension and random idea starters you, most likely, have tried previously.

\author{
Authors: \\ Linda Conway Correll George, Retired Professor, University of Florida, USA \\ Dr. Arpan Yagnik, Assistant Professor, Advertising, Penn State University, USA \\ ISBN: 9789386446824 \\ Price: 395 INR \\ Publications: SAGE Publications India Pvt Ltd, New Delhi
}

